\title{
Outcomes following management of Squamous Cell Carcinoma of the Scalp: a retrospective series of 235 patients treated at the Peter MacCallum Cancer Centre.
}

\author{
Vanessa Estall $^{1,2}$, Angela Allen ${ }^{3}$, Angela Webb $^{1}$, Mathias Bressel ${ }^{1}$, Chris \\ McCormack $^{1}$, John Spilane ${ }^{1,2}$
}

${ }^{1}$ Liverpool Hospital Cancer Therapy Centre, Sydney NSW 2071, Australia ${ }^{2}$ University of Melbourne, Parkville VIC 3010, Australia

${ }^{3}$ Waikato Regional Cancer Centre, Hamilton, New Zealand

${ }^{43}$ PeterMacCallum Cancer Centre, Melbourne VIC 3002, Australia

Abbreviated Title: Outcomes following management of SCC scalp.

Key terms: cutaneous squamous cell carcinoma, scalp, immunosuppression, outcomes

Word count: Title page 140, Abstract 197, Capsule Summary 93, Manuscript 2468, References 872

Number of figures and tables: Figures 7, Tables 8

Number of references: 30

Corresponding author: Dr Vanessa Estall BHB MBChB, FRANZCR, MD

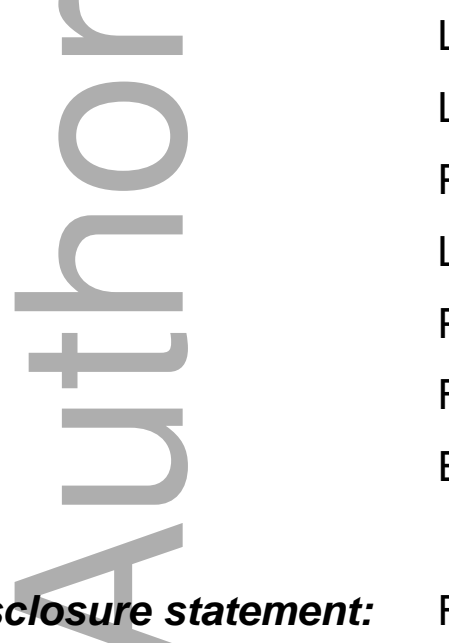
Liverpool Hospital Cancer Therapy Centre Locked bag 7103 PO Box 149

Liverpool 1871

Phone: +61287389806

Fax: +61287389819

Email: vjestall@hotmail.com

Disclosure statement: Funding sources: None

Conflicts of interest: None declared

This is the author manuscript accepted for publication and has undergone full peer review but has not been through the copyediting, typesetting, pagination and proofreading process, which may lead to differences between this version and the Version of Record. Please cite this article as doi: 10.1111/ajd.12520

This article is protected by copyright. All rights reserved 
2 Received Date : 19-Jan-2016

3 Revised Date : 26-Apr-2016

4 Accepted Date : 29-Apr-2016

5 Article type : Original Research

\section{Abstract}

Background

10 Squamous cell carcinoma (SCC) of the scalp is a common clinical problem in an

11 aging population. Despite its high incidence, little has been documented regarding

12 treatment or outcomes.

13 Methods

14 We retrospectively analysed 235 cases treated with curative intent at Peter MaCallum Cancer Centre, between 1998 and 2010. The cohort was analysed for demographics, management, survival and prognostic factors.

\section{Results}

18 The patients were primarily male (88\%) with a median age of 79yrs (range 53-98).

19 There was a high proportion of patient immunosuppression (29\%) and stage T2 $20(48 \%)$ tumours. Management included surgery (45\%), radiotherapy (28\%) and 21 surgery and adjuvant radiotherapy (26\%). Median follow up from treatment was 22 4.5yrs. Estimated 5yr overall survival (OS), disease specific survival (DSS) and 23 progression free survival (PFS) were 59\%, 94\% and 51\% respectively. The 5yr 24 cumulative incidence of local and regional relapse was $11.1 \%$ and $6.9 \%$ respectively.

25 There were 4 patients who developed distant metastases and died of their disease.

26 Statistically significant prognostic factors identified for poor outcomes for OS and 27 PFS were T2 stage (Hazard ratio 1.7 and 2.1) and immunosuppression (Hazard ratio 283.3 and 3.4).

29 Conclusions

30 We conclude the presence of immunosuppression and T2 stage is prognostic for 31 survival. Further research to establish treatment principles is warranted.

\section{Introduction}


34 Squamous cell carcinoma (SCC) of the scalp is a significant issue in Australia $(1,2)$.

35 Lesions on the scalp account for $2 \%$ of all skin cancers and $10-20 \%$ of lesions in the head and neck region $(3,4)$. The incidence of SCC is significant in the elderly population (2) with men at particular risk of primary lesions on the scalp due to chronic sun exposure of this area. Clinical outcomes are assumed to be similar to SCC involving other parts of the head and neck region, with most series reporting all head and neck SCC's in the same cohort.

Few studies address the challenges of management and outcomes in the treatment of SCC of the scalp. In a large review of the Finnish cancer registry from 1967 to 1981 , men with SCC of the scalp had a worse overall survival compared to the general cohort (80.2\% vs. $87.8 \%$ ) (5). Multiple publications have proposed the scalp as a high-risk site for $\operatorname{SCC}(6,7,8,9)$, however the number of scalp cases analysed were small. The $7^{\text {th }}$ edition of the Tumour Node Metastases (TNM) classification for NMSC by the American Joint Committee on Cancer (AJCC) incorporates risk factors for nodal metastases disease into the $T$ stage in addition to tumour size (10). The scalp has not been included as a 'high-risk' site in the updated AJCC staging system. The National Comprehensive Cancer Network (NCCN) recommends SCC be stratified into a low or high risk of recurrence based on a tiered classification of anatomical sites, defining scalp SCC's as medium risk (11).

Due to the limited data available in the literature on this topic and inconsistency of recommendations, we performed a retrospective review of our practice to determine outcomes for patients with scalp SCC particularly with respects to patients with immune-suppression.

\section{Methods}

61 We conducted a retrospective review of patients with histologically proven, primary 62 SCC of the scalp treated with curative intent between 1998 and 2010 at the Peter 63 MacCallum Cancer Centre (PMCC), which is a large tertiary referral cancer hospital. 
65 Patients were identified using the hospital's Division of Pathology and Radiation 66 Oncology databases. Patient demographics, primary tumour characteristics and 67 outcomes were recorded. We considered immuno-suppression as; co-existing 68 haematological malignancy (including Hodgkin's/non-Hodgkin's lymphoma, chronic 69 lymphocytic leukemia), immunosuppressant use (defined as prednisolone 5mg or more a day and/or other immunosuppressive agents for longer than one year), and end stage renal failure requiring dialysis. Tumour factors collected are reported in Table 1 and included SCC grade defined as G1 (well differentiated), G2 (moderately differentiated) and G3 (poorly differentiated). T stage was defined using the $7^{\text {th }}$ edition TNM staging for NMSC (9), which allows T1 tumours <2cm in diameter to upstaged to T2 if they have 2 of the following features; $>2 \mathrm{~mm}$ thickness, Clark level $>\mathrm{IV}$, perineural invasion, primary site ear or hair bearing lip, poorly differentiated or undifferentiated.

Primary treatment was recorded as surgery, radiotherapy or surgery followed by adjuvant radiotherapy. The treatment start date was taken as the date of surgery or the first day of radiotherapy. A recurrence was defined as local (within $2 \mathrm{~cm}$ of the primary lesion), regional (first echelon lymph node metastases) or metastatic (beyond the first echelon lymph node region).

Overall survival (OS), disease specific survival (DSS) and progression free survival (PFS) were calculated from the date of treatment, and the survival curves were reported using Kaplan-Meier methods. Log rank test was used to assess the impact of risk factors on OS and PFS for univariate analysis while Cox proportional hazard models were used for multivariate analysis. All statistical analyses were performed in R (version 3.0.1; R Development Core Team 2009).

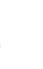

(1)

\section{Results}

\section{Patient characteristics}


94 Data was collected for 235 patients. The majority of patients (88\%) were male and

95 the median age at diagnosis was 79 years (range 53-98). Immunosuppression was present in $29 \%$ (Table 1).

97

98

\section{Primary lesion characteristics}

99 The primary lesions characteristics are shown in Table 1. Despite the majority of 100 lesions being less than $20 \mathrm{~mm}$ (63\%), the proportion of stage T2 lesions was $52 \%$ 101 due to $78 \%$ of lesions graded as G2 and G3. Depth of invasion and presence or 102 absence of in-situ disease was rarely recorded in pathology reports or notes and 103 therefore not included in the analysis. No patients were found to have had nodal 104 disease at the time of first presentation.

105

\section{Treatment}

107 Of the 235 patients analyzed, $45 \%$ had definitive surgery, $28 \%$ had definitive 108 radiotherapy and $26 \%$ had surgery followed by adjuvant radiotherapy. In patients 109 who had surgery as primary therapy, margin status was difficult to assess, as this 110 information was not documented in $29 \%$ of reports. Of the cases in which margin 111 status was available, $24 \%$ were noted to be positive and the majority of these (78\%) 112 had been referred directly for adjuvant radiotherapy following surgery performed 113 outside of our institution. Re-excision was performed by our surgeons in 9 patients 114 and clear margins achieved in 4. All patients that did not have a re-excision received 115 adjuvant radiotherapy.

116 Radiotherapy was delivered with adjuvant intent to the primary tumour bed in $26 \%$ 117 with a range of dose from 32Gy to 66Gy. Prophylactic radiotherapy was delivered to 118 draining lymph node basins in only 3 cases relapsed cases receiving salvage 119 treatment, with doses ranging from 55Gy to 60Gy. Definitive radiotherapy was 120 delivered in $28 \%$ of cases with a range of dose from 32Gy to 70 Gy.

\section{Survival}


123 The median follow up time from date of first treatment was 4.5 years. The estimated

1245 year overall survival (OS), disease specific survival (DSS) and progression free

125 survival (PFS) was 59\%, 94\% and 51\% respectively (see Figure 1, 2, and 3).

126

127 First site of relapse

128 Recurrence overall was documented in 35 (14.9\%) patients following treatment, with

12921 local and 14 regional relapses. The estimated cumulative incidence of local and 130 regional relapse at $5 y$ rs was $11.1 \%$ and $6.9 \%$ respectively. The majority of 131 recurrences occurred in the first year (local 7.3\% and regional 4.5\%), and the 132 incidence of recurrence reached a plateau at 3 years.

Local relapse

134 The characteristics of the 21 cases where local relapse was the initial site of failure 135 are presented in Table 2. Most were stage T2 and did not receive adjuvant 136 radiotherapy. Of the patients who recurred locally, 14\% were immunosuppressed. $\underline{\text { Regional relapse }}$

The characteristics of cases where regional nodal relapse was the initial site of failure are presented in Table 2. These were similar to those associated with local relapse, apart from immunosuppression which was present in $50 \%$ of patients with regional relapse versus $29 \%$ with local relapse. The majority of these cases $(9 / 14)$ had received adjuvant radiotherapy to the primary site, but none had received prophylactic treatment to draining lymph node basins.

Curative treatment was attempted in all 35 patients after an initial relapse. Of the 21 patients that developed a local recurrence and received salvage treatment, 4 relapsed again ( 3 adjacent lymph nodes, 1 distant). Of the 14 patients that developed a regional recurrence and received salvage treatment, 5 relapsed again (2 in regional lymph nodes, 3 distant). 
151 There were no cases of distant recurrence as the initial site of relapse. All 4 patients 152 who developed distant metastases following initial or local relapse, died of their SCC 153 scalp.

154

\section{Prognostic factors}

156 On univariate analysis the factors significant for poorer outcome for OS were 157 immunosuppresion, T stage, size and type of treatment (Table 3), and these same

158 factors in addition to positive margins and presence of LVI were signifcant for poorer 159 outcome for PFS (Table 4). On multi-variatine only immunosuppression and T stage remained significant for both. For OS the hazard ratio (HR) for immunosuppression in the multi factor model was $3.4[95 \% \mathrm{Cl}(2.2-5.1)]$ and the HR for T stage in the multifactor model was 1.7 [95\%

$164 \mathrm{Cl}(1.1-2.5)]$. For PFS the HR for immunosuppression in the multifactor model was $1653.3[95 \% \mathrm{Cl}(2.3-4.9)]$ and the $\mathrm{HR}$ for T stage in the multifactor model was 2.1 [95\% $\mathrm{Cl}(1.4-3.1)]$.

The 5yr DSS for Stage T1 versus T2 was $100 \%$ and $88 \%$ respectively (Figure 4). The $5 \mathrm{yr}$ DSS for immune competent patients versus immune compromised patients was $96 \%$ and $87 \%$ respectively (Figure 4 ).

The 5yr PFS for Stage T1 versus T2 was $67 \%$ and $36 \%$ respectively (Figure 5). The $5 y$ PFS for immune competent patients versus immunocompromised patients was $62 \%$ and $27 \%$ respectively (Figure 5 ).

\section{Discussion}

178 To our knowledge this is the largest reported cohort of patients $(n=235)$ with primary

179 scalp SCC treated with curative intent. The majority of our patients were elderly men, 180 and were managed with surgery, radiotherapy or a combination of both modalities, 181 consistent with other reports. No patients had nodal disease at presentation, and the 182 role of staging was not assessed. We had a large representation of patients with high 183 risk disease with $52 \%$ of tumours being $\mathrm{T} 2$ and $78 \%$ being moderately or poorly 
184 differentiated, and almost a third of patients (29\%) being immunosuppressed. This

185 may reflect the referral patterns and nature of our unit, which is within the context of a 186 large 'cancer only' hospital.

188 On reviewing the literature we have found only 3 other small studies addressing 189 scalp specific populations, and another 2 addressing general skin cancer populations 190 which included scalp patients. A comparison of these studies and ours are provided 191 in Table 5. Mohs et al reported on a cohort of 83 scalp patients with good outcomes 192 following Mohs surgery (12). Lang et al reported on a series of 11 scalp cases 193 treated with Mohs microsurgery, which then progressed in an aggressive fashion.

194 They noted a higher than expected rate of death due to SCC (5/11 patients) but 195 prognostic factors were poorly reported (4). Howle et al reported on the outcomes 196 and prognostic factors for 27 patients who developed metastatic nodal disease from 197 a scalp SCC primary. The 5yr DSS was 59\% reflecting the impact of nodal relapse 198 on survival outcomes (13). Schumults et al (14) assessed 985 patients with 1832 199 treated invasive SCC's from all sites, with a median follow up of 50 months. The OS, 200 loco- regional DFS and DSS at 5 years were 68\%, 96\% and $97 \%$ respectively.

201 Overall local recurrence was 4.6\%, nodal recurrence was 3.7\% and $2.1 \%$ of patients 202 died as a result of their SCC. Brantsch et al (15) reported on a prospective trial of 203615 patients, documenting local and regional recurrence rates of $3 \%$ and a $4 \%$.

205 The survival outcomes were slightly worse for our cohort of scalp SCC patients in 206 comparison to those previously published. The 5yr OS of $59 \%$ and DSS of $94 \%$ 207 suggest only a small proportion of patients died from their SCC scalp specifically, 208 with the majority succumbing to age related co-morbidities. However, overall 209 recurrence was $15 \%$ in our cohort, compared to 4-5\% noted in series assessing SCC 210 from all sites $(14,15)$. PFS at 5yrs was $51 \%$ indicating that the likelihood patients 211 would relapse following initial treatment was high, but in most cases this was 212 successfully salvaged. Our poorer control and survival outcomes are most likely a 213 reflection of selection bias, as we demonstrated a statistically significant reduction in 214 PFS and OS in the setting of increased stage of the primary lesion above T2 (HR 215 2.1), and in the presence of host immunosuppression (HR 3.3). We had high 216 proportions of both these prognostic factors in our group. 
218 Our finding that T2 primary lesions are associated with a worse OS and PFS 219 indicates that accurate T staging of primary lesions is important for prognostication 220 and treatment planning. Despite this, a third of pathology reports in our cohort did not 221 document prognostic factors for accurate T staging of SCC with depth of invasion, 222 status of PNI and LVI and margin status often omitted. Synoptic reporting is currently 223 recommended for melanoma, and there may be a role for a similar type of report in 224 for SCC, to ensure that the small percentage of 'high-risk' lesions are easily identified 225 and managed appropriately at diagnosis.

227 Following accurate staging, adequate surgical management of the primary lesion is 228 the gold standard of treatment. The impact of margin status on outcomes remains unclear, and the heterogeneity and poor documentation of the margin status in our cohort makes the results difficult to interpret. Of the 41 patients with documented 231 positive margins, the majority of cases were positive at the deep margin (32/41), 232 which is not un-expected for scalp lesions. In the group identified by Howle et al (7), 233 a high proportion of patients with nodal spread had close or positive margins (51\%) 234 following treatment of the primary lesion. In the absence of clear evidence, basic 235 oncological principles indicate clear margins should be the surgical goal. This approach is supported by surgical series suggesting that clear margins are associated with very low rates of recurrence, particularly if margins of $>2-4 \mathrm{~mm}$ can be achieved $(16,17,18,19)$. In order to achieve this in the scalp, it may be necessary to consider re-excision, removal of periosteum or even removal of the outer table of the skull.

242 Host immunosuppression is now accepted as an important risk factor for adverse 243 outcomes following management of SCC, and our results have further confirmed this. 244 Immunosuppression is associated with an increased risk of nodal metastases, distant 245 metastases and death from SCC as shown by multiple studies $(20,21,22,23)$. In our 246 series, the 5yr PFS for immune-competent versus immune-compromised patients 247 was 62 vs. $27 \%$, with half of the patients who developed regional recurrence being 
248 immuno-compromised. Although deaths from SCC are rare, in our and other cohorts

249 most patients who died from their disease did so in the setting of nodal metastases $250(7,24,25)$.

252 Although not statistically significant, patients in our study who developed recurrent 253 disease had poorer survival outcomes following salvage treatment with high rates of 254 regional (14.3\%) and distant relapse (11.4\%). Lebovitch et al demonstrated a 255 statistically significant increased risk of recurrence of $6.9 \%$ vs. $2.6 \%$ in patients 256 treated for recurrent versus primary SCC (26). Mohs et al demonstrated a 5year cure 257 rate of SCC of the scalp was $98.8 \%$ following Mohs microsurgery. However the 258 presence of recurrent disease reduced the chance of cure to $90 \%$ (12). This 259 suggests that prevention of local and regional relapse following the first presentation 260 may be of significant value. The role of prophylactic surgery or radiotherapy of the 261 clinically node negative neck remains unclear in this setting due to a lack of high 262 quality clinical data. Only 3 of our patients received prophylactic nodal radiotherapy 263 to draining lymph nodes at relapse, and none at first presentation, so we are unable 264 to comment on its efficacy in this setting. However, elective nodal irradiation has 265 been addressed in other series of SCC patients, showing it can reduce the risk of 266 regional lymph-node recurrence in patients with high risk primary disease $(27,28$, 267 29). Therefore, it could be considered in high-risk cases, but patients must be 268 selected following an individualized risk: benefit analysis, acknowledging that 269 enlarging treatment fields can have a significant impact on toxicity and quality of life, which may not be appropriate in some patients. More accurate nodal staging may 271 aid in better patient selection for aggressive treatment. Sentinel lymph node biopsy 272 (SLNB) in the staging of SCC has been investigated in small series and may be 273 feasible, identifying occult nodal metastases in $20 \%$ of cases (30). Where available 274 this could be useful in the setting of scalp SCC where lymphatic drainage is 275 unpredictable, and could aid patient selection for elective nodal treatment versus 276 observation.

278 In summary, we have presented a large cohort of scalp SCC cases and found that, 279 although the majority of patients do well, there is a group who may have significantly 
poorer outcomes. Patients with T2 primary lesions and immunosuppression have a lower OS and PFS, and although there is no evidence at this point that more aggressive management of these patients will result in improved survival outcomes, it is reasonable to offer treatments aimed at maximizing loco-regional control. SCC's of the scalp will become a more common problem with an aging population, and future research into the utility of staging and prophylactic nodal treatment of the clinically negative neck is warranted.

References

1. Australian Institute of Health and Welfare \& Cancer Australia (2008). Nonmelanoma skin cancer. General practice consultations, hospitalisation and mortality Cancer Series 2008: No 43

2. Staples, M. P., M. Elwood, R. C. Burtonete al.. Non-melanoma skin cancer in Australia: the 2002 national survey and trends since 1985. Med J Aust. 2006: 184(1):6-10.

3. Czarnecki, D., M. Staples, A. Mar et al. Metastases from squamous cell carcinoma of the skin in southern Australia. Dermatology. 1994; 189(1): 52-54.

4. Lang, P. G., M. A. Braun and R. Kwatra. Aggressive squamous carcinomas of the scalp. Dermatol Surg 2006; 32(9): 1163-1170.

5. Karjalainen, S., H. Salo and L. Teppo. Basal cell and squamous cell carcinoma of the skin in Finland. Site distribution and patient survival. Int $J$ Dermatol 1989; 28(7): 445-450.

6. Nolan, R. C., M. T. Chan and P. J. Heenan. A clinicopathologic review of lethal nonmelanoma skin cancers in Western Australia. J Am Acad Dermatol. 2005; 52(1): 101-108. 
7. Edge, S. B. and C. C. Compton. The American Joint Committee on Cancer: the 7th edition of the AJCC cancer staging manual and the future of TNM. 2010; 17(6): 1471-1474.

8. Dinehart SM, Peteron S. Evaluation of the American Joint Committee on Cancer Staging System for cutaneous squamous cell carcinoma and proposal of a new staging system. Dermatol Surg. 2005;31(11):1379-84.

10. Warner CL, Cockerell CJ. The new seventh edition American Joint Committee

9. Veness, M. J. High-risk cutaneous squamous cell carcinoma of the head and neck. J Biomed Biotechnol 2007; (3): 80572. on Cancer Staging of Cutaneous Non-Melanoma Skin Cancer. Am J Clin Dermato. 2011; 12 (3):147-154.

11. Miller SJ, Alam M, Anderson J et al. NCCN practice guidelines in oncology: basal cell and squamous cell skin cancers. Version 1, 2009 (http://www.nccn.org)

12. Mohs, F. E. and J. A. Zitelli. Microscopically controlled surgery in the treatment of carcinoma of the scalp. Arch Dermatol 1981; 117(12): 764-769.

13. Howle, J. R., G. J. Morgan, I. Kalnins et al. Metastatic cutaneous squamous cell carcinoma of the scalp. ANZ J Surg.2008; 78(6): 449-453. 
16. Jambusaria-Pahlajani, A., Miller, CJ., Quon, H. et al. Surgical monotheraoy versus surgery plus adjuvant radiotherapy in high-risk cutaneous squamous cell carcinoma: a systematic review of outcomes. Dermatol Surg 2009; 35(4):574-585.

17. Brodland DG,. Zitelli, JA.Surgical margins for excision of primary cutaneous squamous cell carcinoma. J Am Acad Dermatol_1992; 27:241-248.

18. Tan, PY., Ek, E., Giorlando F. Incomplete excision of squamous cell carcinoma of the skin: a prospective observational study. Plast Reconstr Surg 2007; 120(4):910-916.

19. Broadland, DG., Zitelli, JA. Surgical margins for excision of primary cutaneous squamous cell carcinoma. JAAD_1992; 27: 241-248.

20. Cooper, J. Z. and M. D. Brown. Special concern about squamous cell carcinoma of the scalp in organ transplant recipients. Arch Dermatol 2006; 142(6): 755-758.

21. Rowe, D. E., R. J. Carroll and C. L. Day.Prognostic factors for local recurrence, metastasis, and survival rates in squamous cell carcinoma of the skin, ear, and lip. Implications for treatment modality selection. J Am Acad Dermatol 1992; 26(6): 976-990.

22. Tomaszewski, J. M., H. Gavriel, E. Link, S. et al. Aggressive behavior of cutaneous squamous cell carcinoma in patients with chronic lymphocytic leukemia. Laryngoscope 2014; 124(9): 2043-2048.

23. Frierson, H. F., B. D. Deutsch and P. A. Levine.Clinicopathologic features of cutaneous squamous cell carcinomas of the head and neck in patients with chronic lymphocytic leukemia/small lymphocytic lymphoma. Hum Pathol 1988; 19(12): 1397-1402. 
24. Clayman, G. L., J. J. Lee, F. C. Holsinger et al. Mortality risk from squamous cell skin cancer. J Clin Oncol 2005; 23(4): 759-765.

\section{5. http://www.cancer.org.au/about-cancer/types-of-cancer/skin-cancer.html}

26. Leibovitch, I., S. C. Huilgol, D. Selva et al. Cutaneous squamous cell carcinoma treated with Mohs micrographic surgery in Australia I. Experience over 10 years. 2005; 53(2): 253-260.

27. Khan, L., D. Breen, L. Zhang et al. Predictors of recurrence after radiotherapy for non-melanoma skin cancer. Curr Oncol 2014; 21(2): e326-329.

28. O'Brien, C. J. The parotid gland as a metastatic basin for cutaneous cancer. Arch Otolaryngol Head Neck Surg. 2005; 131(7): 551-555.

29. Veness, M. J., C. E. Palme and G. J. Morgan. High-risk cutaneous squamous cell carcinoma of the head and neck: results from 266 treated patients with metastatic lymph node disease. 2006; 106(11): 2389-2396

30. Ross AS, Schmults CD.Sentinal lymph node biopsy in cutaneous squamous cell carcinoma: a systematic review of the English literature. Am Soc Derm Surg. 2006; 32 :1309-1321.

Figures

Figure 1 Overall survival (OS) for primary SCC of the scalp

Figure 2 Disease specific survival (DFS) for primary SCC of the scalp Figure 3 Progression free survival (PFS) for primary SCC of the scalp Figure 4 Disease specific survival (DSS) according to T stage and immunosuppression status 
411 Figure 5 Progression free survival (PFS) according to T stage and immunosuppression status

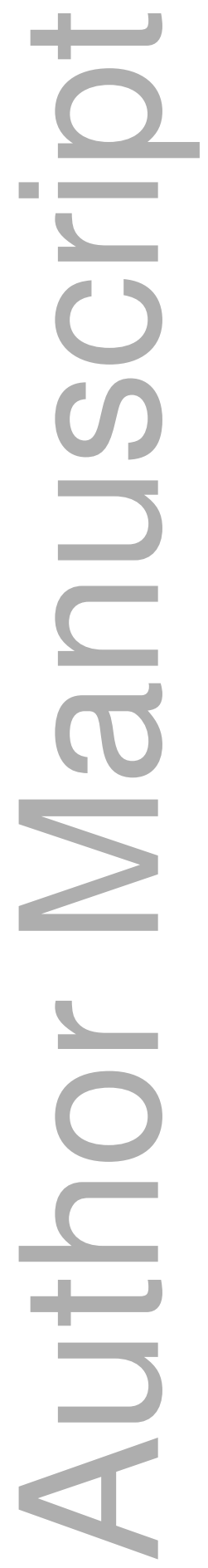


Table 1. Characteristics of 235 patients and primary cSCC scalp lesions.

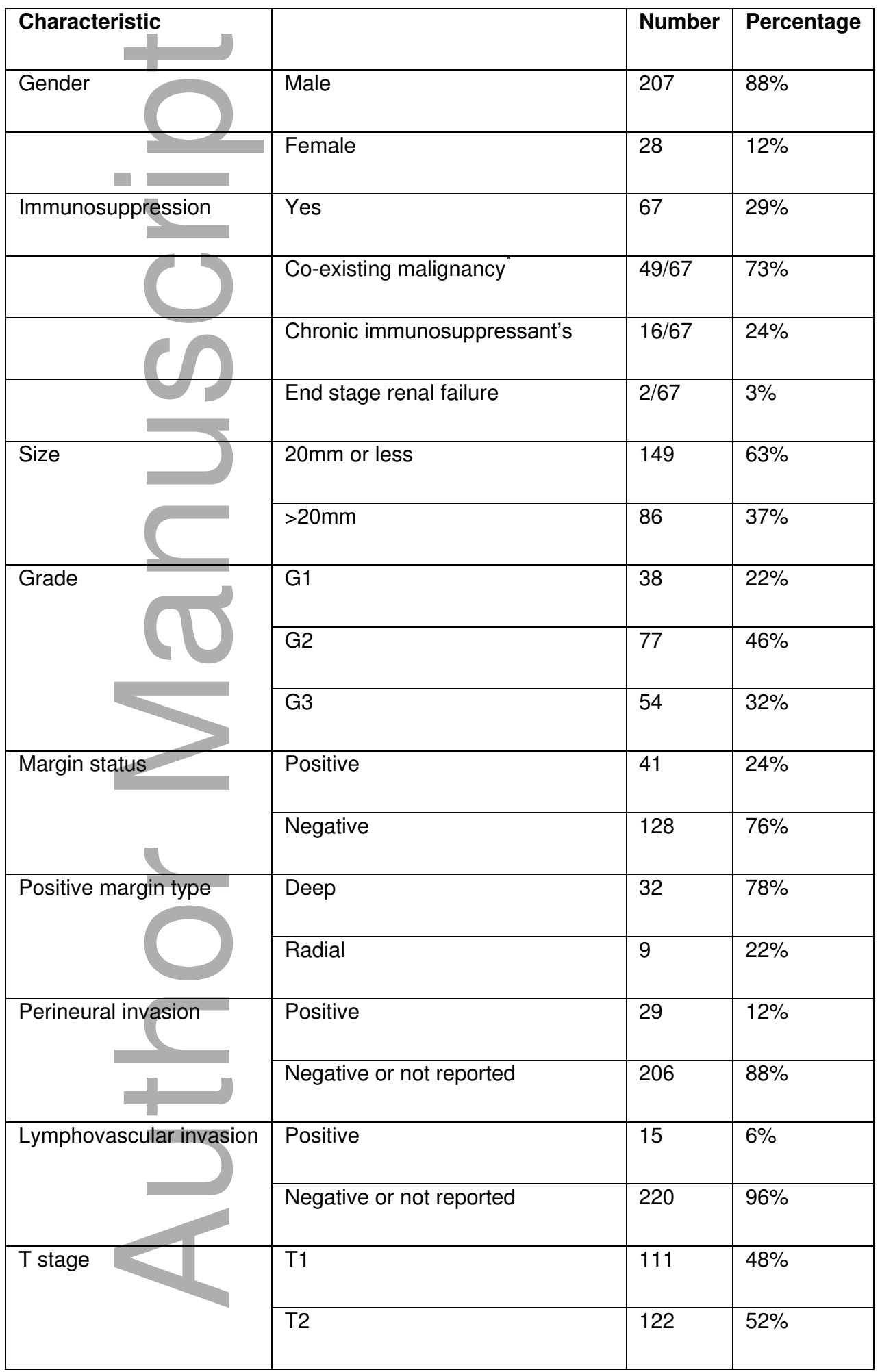

This article is protected by copyright. All rights reserved 


\begin{tabular}{|c|c|c|c|}
\hline & T4 & 2 & $<1 \%$ \\
\hline \multirow[t]{3}{*}{ Treatment m } & Surgery alone & 105 & $45 \%$ \\
\hline & Radiotherapy alone & 66 & $28 \%$ \\
\hline & Surgery and adjuvant radiotherapy & 62 & $27 \%$ \\
\hline
\end{tabular}

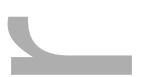

*35/49 (72.5\%) patients with co-existing malignancy had hematological malignancy

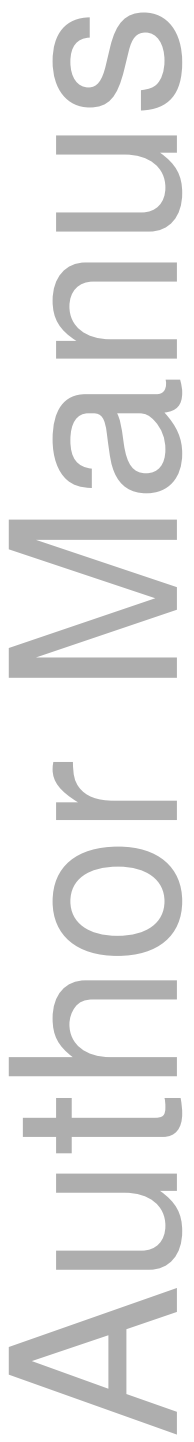

This article is protected by copyright. All rights reserved 
Table 2. Characteristics of local and regional relapse as the first site of recurrence following definitive surgery of the primary lesion

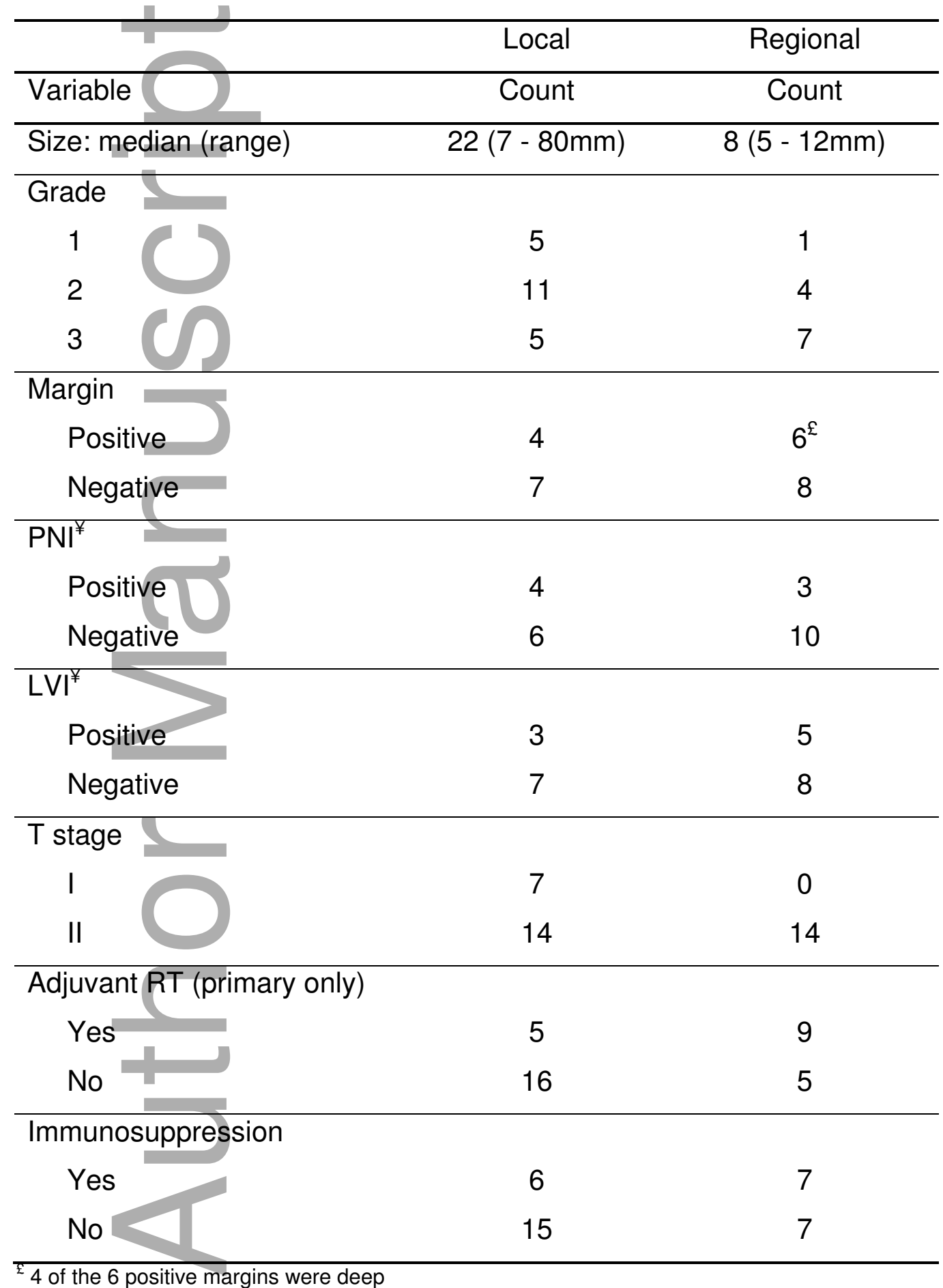

${ }^{\Sigma} 4$ of the 6 positive margins were deep

This article is protected by copyright. All rights reserved 
Table 3. Unifactor analysis of possible risk factors for overall survival.

\begin{tabular}{|c|c|c|c|c|c|}
\hline \multirow{2}{*}{ Variable } & \multicolumn{4}{|c|}{ Coun } & \multirow{2}{*}{$\begin{array}{c}\mathrm{p}- \\
\text { value }\end{array}$} \\
\hline & Category & $\mathrm{t}$ & $\%$ & $\mathrm{HR}(95 \% \mathrm{Cl})$ & \\
\hline \multirow{2}{*}{ Immunosuppression } & No & 168 & 71 & 1 & $<0.001$ \\
\hline & Yes & 67 & 29 & $3.3(2.2-5.0)$ & \\
\hline \multirow[t]{2}{*}{ T Stage $^{1}$} & Stage 1 & 111 & 48 & 1 & 0.013 \\
\hline & Stage 2 & 122 & 52 & $1.7(1.1-2.6)$ & \\
\hline \multirow[t]{3}{*}{ Grade $^{2}$} & Grade 1 & 38 & 22 & $0.9(0.7-1.3)$ & 0.608 \\
\hline & Grade 2 & 77 & 46 & & \\
\hline & Grade 3 & 54 & 32 & & \\
\hline \multirow[t]{3}{*}{ Size } & $20 \mathrm{~mm}$ or less & 149 & 63 & 1 & 0.013 \\
\hline & More than & & & & \\
\hline & $20 \mathrm{~mm}$ & 86 & 37 & $1.7(1.1-2.6)$ & \\
\hline \multirow{2}{*}{ Margins positive ${ }^{3}$} & No & 128 & 76 & 1 & 0.399 \\
\hline & Yes & 41 & 24 & $1.3(0.7-2.1)$ & \\
\hline \multirow[t]{2}{*}{ Margin type ${ }^{4}$} & Deep & 32 & 78 & 1 & 0.737 \\
\hline & Radial & 9 & 22 & $0.8(0.3-2.4)$ & \\
\hline \multirow{2}{*}{ Closest deep margin ${ }^{5}$} & $<1 \mathrm{~mm}$ & 27 & 71 & 1 & 0.660 \\
\hline & $1 \mathrm{~mm}$ or more & 11 & 29 & $0.8(0.3-2.4)$ & \\
\hline \multirow[t]{2}{*}{ PNI } & No & 206 & 88 & 1 & 0.247 \\
\hline & Yes & 29 & 12 & $1.4(0.8-2.4)$ & \\
\hline
\end{tabular}




\begin{tabular}{llcccc}
\hline LVI & No & 220 & 94 & 1 & 0.899 \\
& Yes & 15 & 6 & $0.9(0.4-2.2)$ & \\
\hline Treatment & RT & 66 & 28 & 1 & 0.031 \\
& Surgery & 105 & 45 & $0.6(0.3-0.9)$ & \\
& Surgery + RT & 62 & 27 & $0.9(0.5-1.7)$ &
\end{tabular}

$\infty$

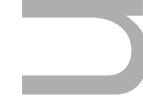
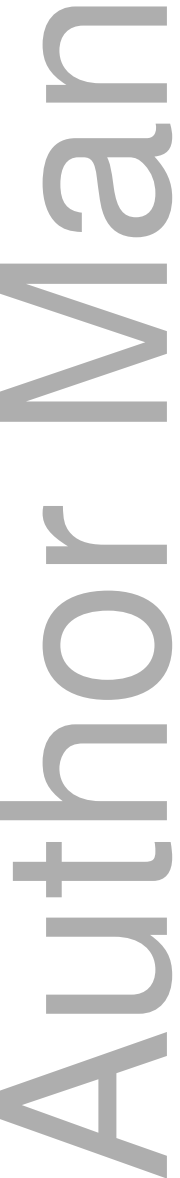

This article is protected by copyright. All rights reserved 
Table 4: Unifactor analysis of possible risk factors for progression free survival.

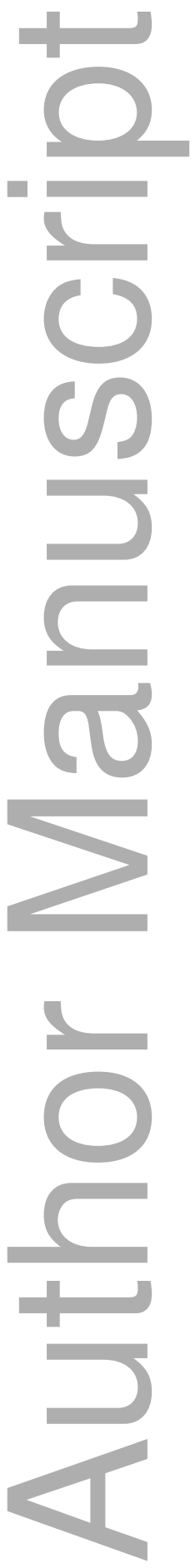

This article is protected by copyright. All rights reserved 
Table 5: Comparison of series data

\begin{tabular}{|c|c|c|c|c|c|c|}
\hline Prognostic factors & $\begin{array}{l}\text { Moh et } \\
\text { al } \\
1981\end{array}$ & $\begin{array}{l}\text { Lang et al } \\
2006\end{array}$ & $\begin{array}{l}\text { Howle } \\
\text { et al }\end{array}$ & $\begin{array}{l}\text { Brantsch et } \\
\text { al } 2008\end{array}$ & $\begin{array}{l}\text { Schmults et } \\
\text { al } \\
2013\end{array}$ & $\begin{array}{l}\text { Estall } \\
\text { et al } \\
2014\end{array}$ \\
\hline Total number & 83 & 11 & 27 & 653 & 1832 & 235 \\
\hline Scalp speci & Yes & Yes & Yes & ND & ND & $100 \%$ \\
\hline H\&N specifi & NA & NA & NA & ND & $28.7 \%$ & NA \\
\hline Male & & $55 \%$ & $96 \%$ & $63 \%$ & $52.7 \%$ & $88 \%$ \\
\hline Size $>20 \mathrm{~mm}$ & & $N D^{* *}$ & $50 \%$ & $31 \%$ & $12.9 \%$ & $37 \%$ \\
\hline MD/PD & & $36 \%$ & $71 \%$ & $47 \%$ & $33.6 \%$ & $78 \%$ \\
\hline $\mathrm{PNI}$ & & ND & ND & $8 \%$ & $4.3 \%$ & $12 \%$ \\
\hline LVI & & ND & ND & ND & ND & $6 \%$ \\
\hline+ margin & & ND & $51 \%$ & 0 & ND & $24 \%$ \\
\hline Immunosuppressed & & ND & $3 \%$ & $5 \%$ & $14.5 \%$ & $29 \%$ \\
\hline $\begin{array}{l}\text { Excision/Mohs } \\
\text { alone }\end{array}$ & $100 \%$ & $100 \%$ & $77 \%$ & $\begin{array}{l}100 \% \text { (with } \\
\text { clear } \\
\text { margins) }\end{array}$ & $89 \%$ & $45 \%$ \\
\hline Radiotherapy alone & & 0 & & 0 & 0 & $28 \%$ \\
\hline $\begin{array}{l}\text { Excision/Mohs + } \\
\text { adjuvant RT }\end{array}$ & & 0 & $23 \%$ & 0 & $1.2 \%$ & $27 \%$ \\
\hline $\begin{array}{l}\text { Other/not } \\
\text { documented }\end{array}$ & & 0 & 0 & 0 & $8.8 \%$ & 0 \\
\hline $5 y r$ OS & & & & & $69 \%$ & $59 \%$ \\
\hline 5yr PFS & $98.8 \%$ & & & $97 \%$ & $83 \%$ & $51 \%$ \\
\hline 5yr DSS & & $54 \%$ & $59 \%$ & & $97.5 \%$ & $94 \%$ \\
\hline
\end{tabular}

This article is protected by copyright. All rights reserved 


\begin{tabular}{|l|l|l|l|l|l|l|}
\hline Local recurrence & & $73 \%$ & & $3 \%$ & $4.6 \%$ & $10.3 \%$ \\
\hline Nodal recurrence & & $27 \%$ & $100 \%$ & $4 \%$ & $3.7 \%$ & $6.9 \%$ \\
\hline
\end{tabular}

*8/11 patients developed satellite lesions and dermal spread, 3/11 developed nodal disease

"*not documented
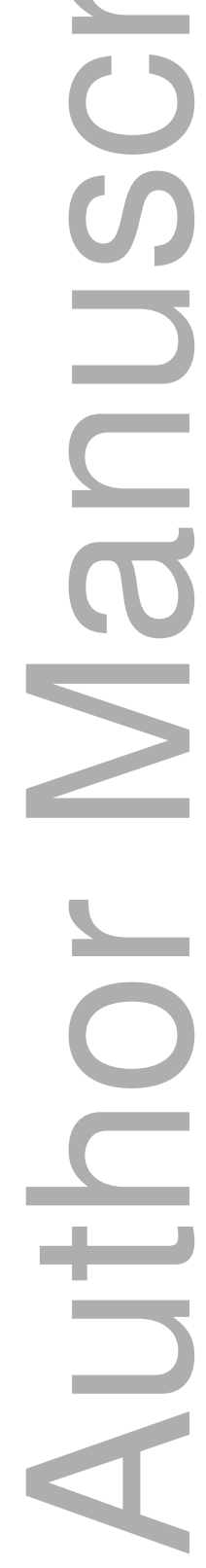

This article is protected by copyright. All rights reserved 

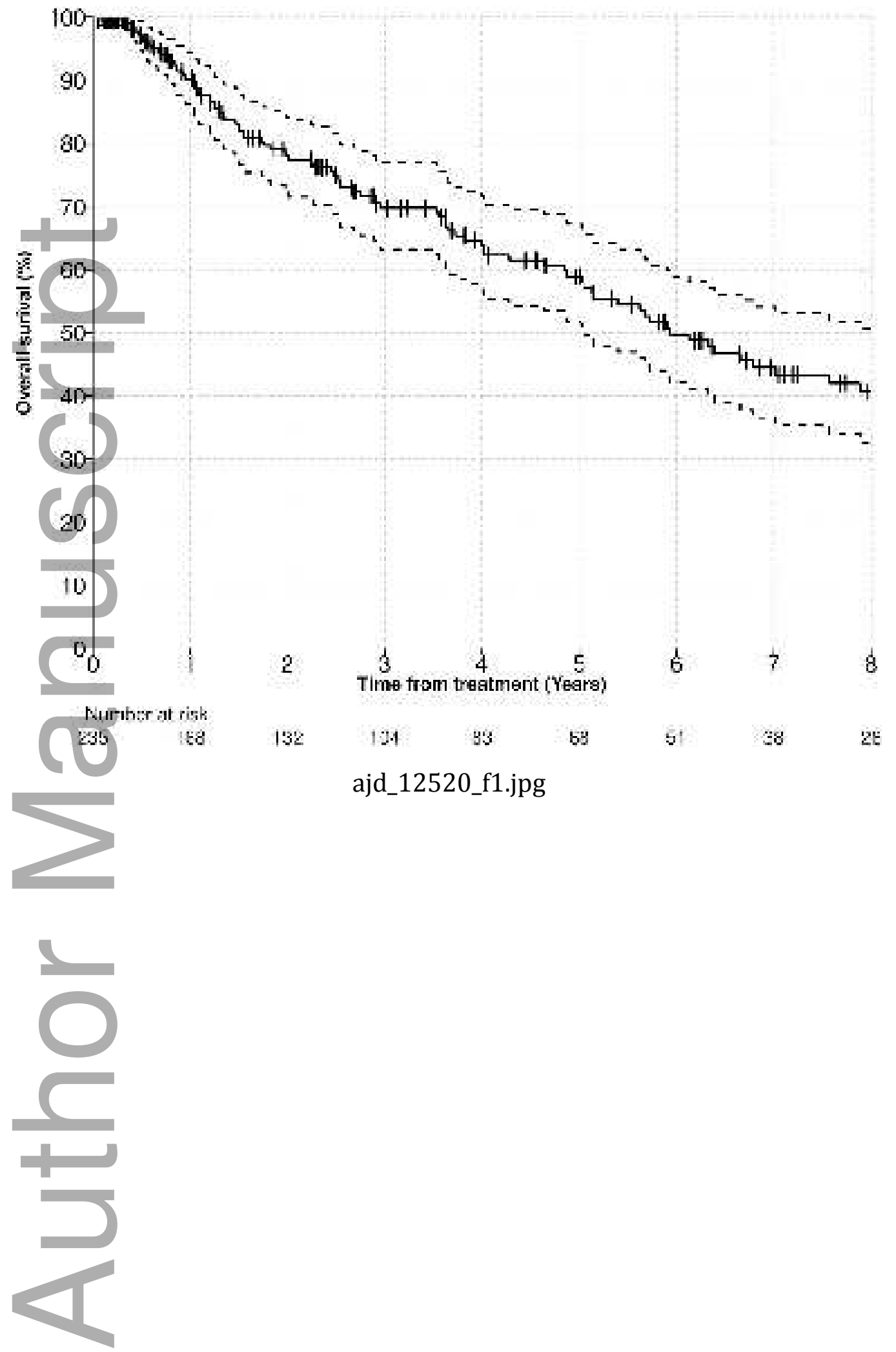

This article is protected by copyright. All rights reserved 

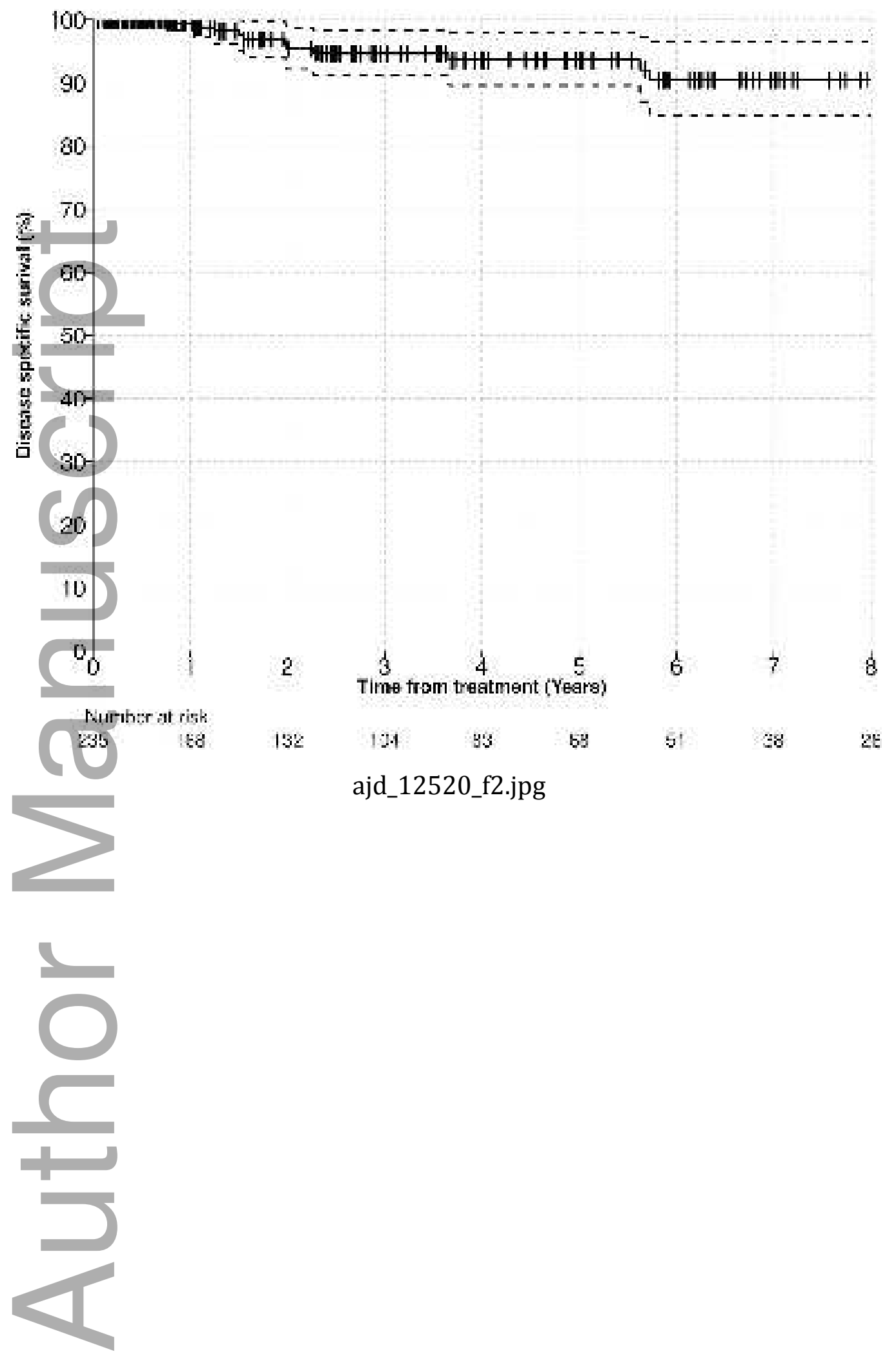

This article is protected by copyright. All rights reserved 

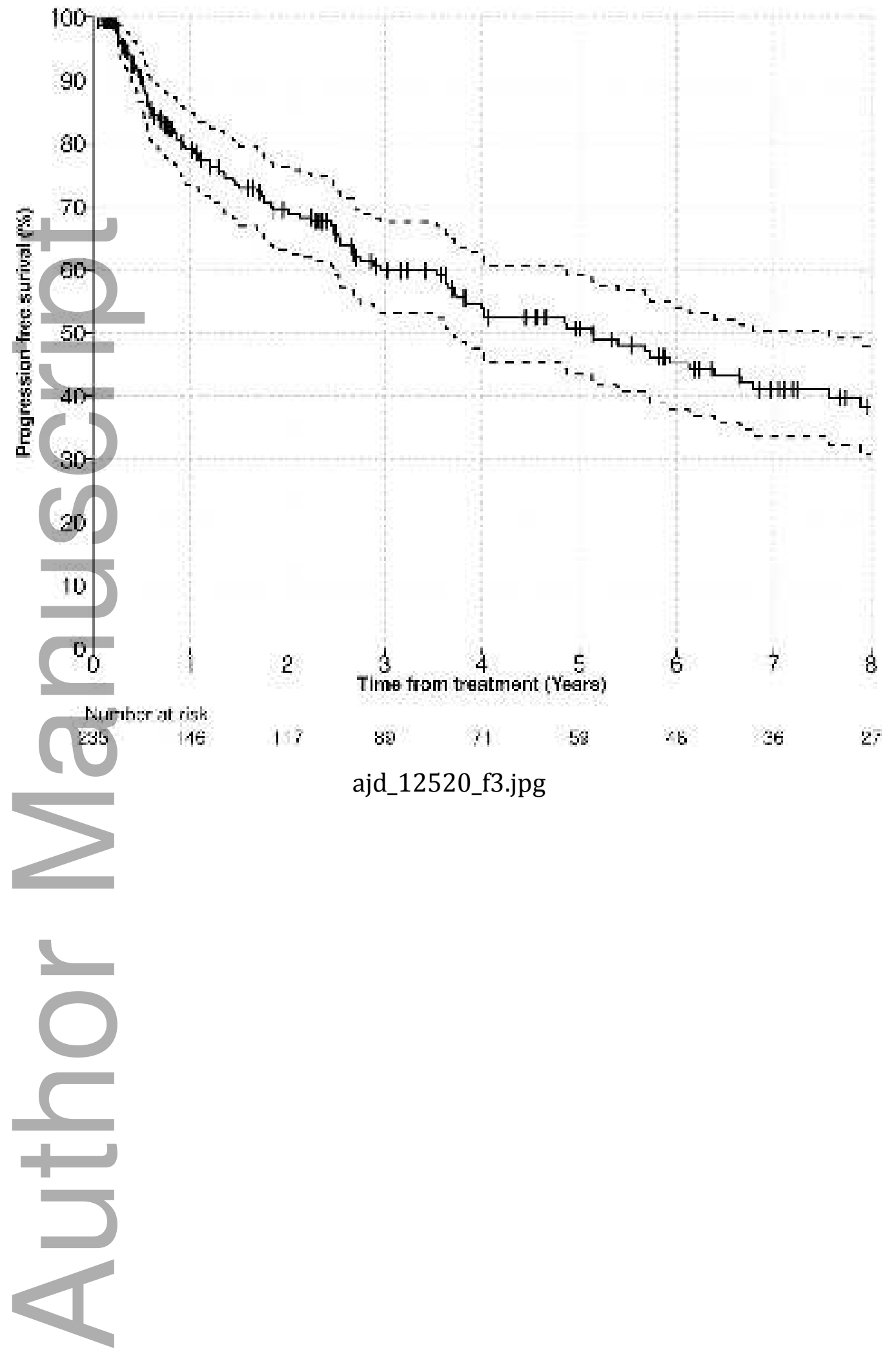

This article is protected by copyright. All rights reserved 


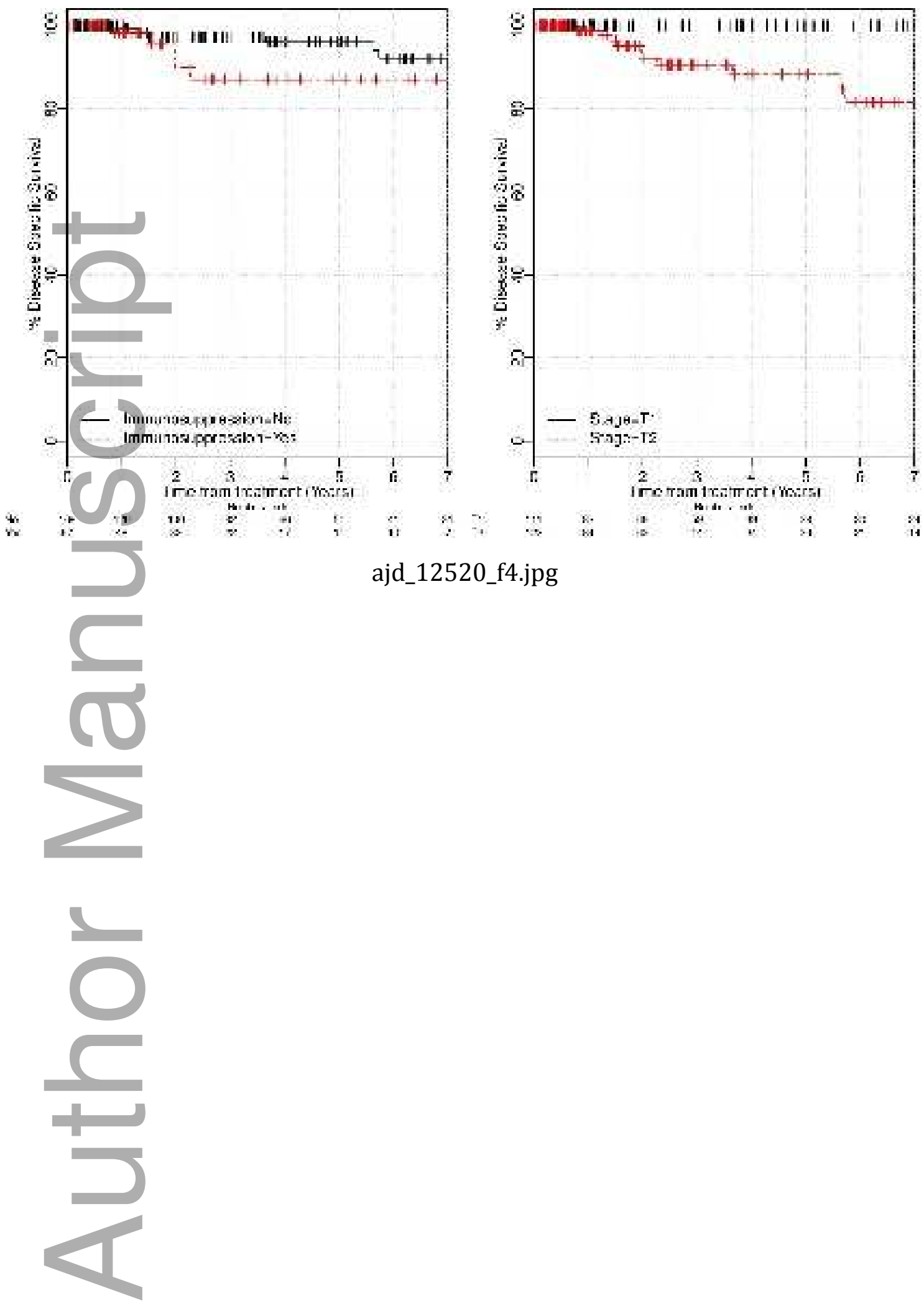

This article is protected by copyright. All rights reserved 

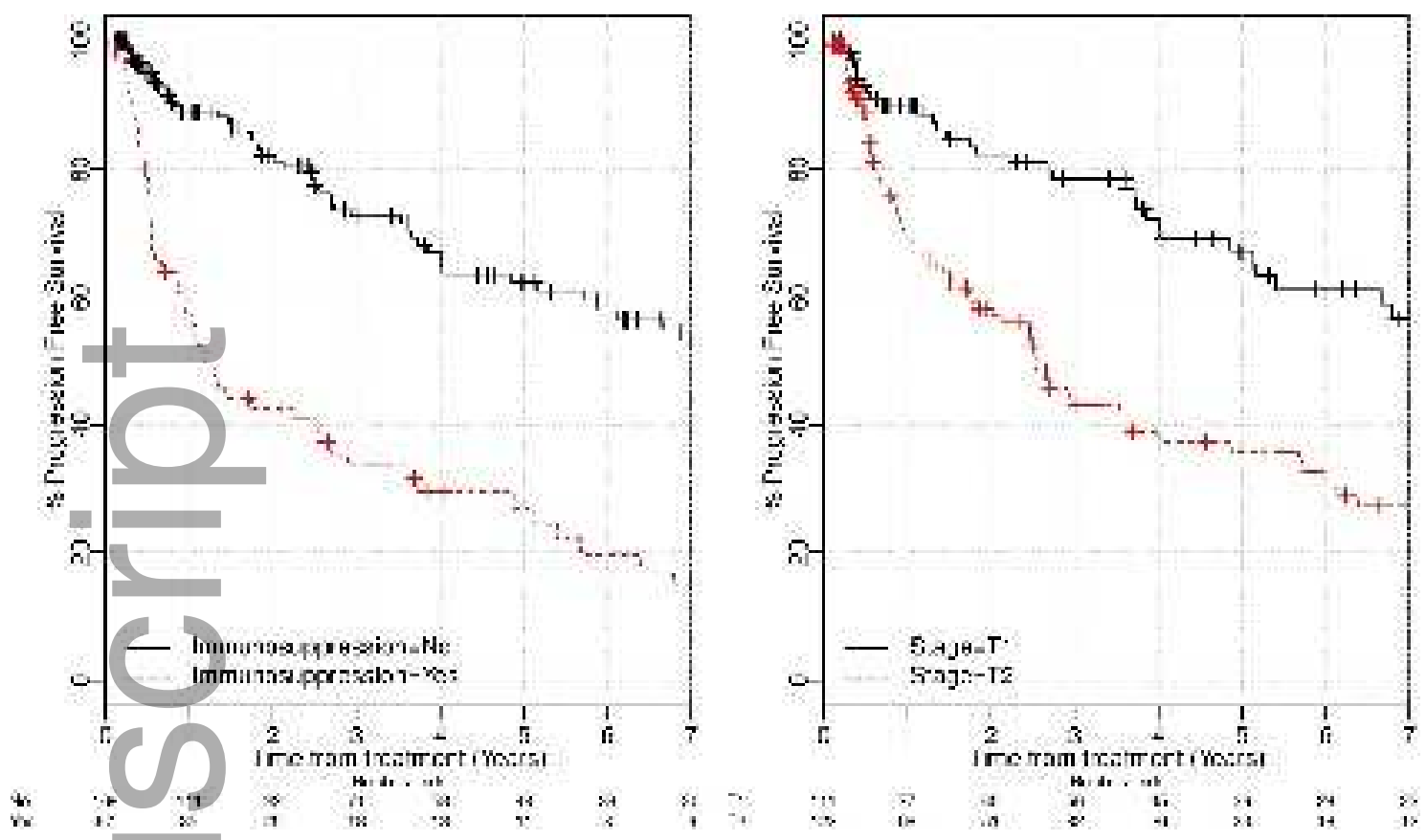

ajd_12520_55.jpg
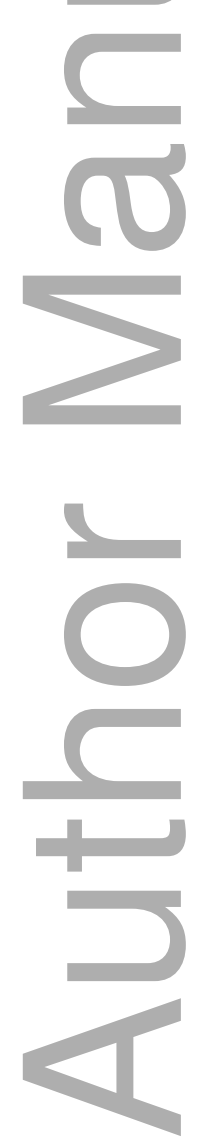

This article is protected by copyright. All rights reserved 


\section{University Library}

\section{- M I N E R VA}

\section{A gateway to Melbourne's research publications}

Minerva Access is the Institutional Repository of The University of Melbourne

\section{Author/s:}

Estall, V;Allen, A;Webb, A;Bressel, M;McCormack, C;Spillane, J

Title:

Outcomes following management of squamous cell carcinoma of the scalp: A retrospective series of 235 patients treated at the Peter MacCallum Cancer Centre

\section{Date:}

2017-11-01

\section{Citation:}

Estall, V., Allen, A., Webb, A., Bressel, M., McCormack, C. \& Spillane, J. (2017). Outcomes following management of squamous cell carcinoma of the scalp: A retrospective series of 235 patients treated at the Peter MacCallum Cancer Centre. AUSTRALASIAN JOURNAL OF DERMATOLOGY, 58 (4), pp.E207-E215. https://doi.org/10.1111/ajd.12520.

Persistent Link:

http://hdl.handle.net/11343/291405 